Article

\title{
Deep Brain Stimulation Is Effective for Treatment-Resistant Depression: A Meta-Analysis and Meta-Regression
}

\author{
Frederick L. Hitti ${ }^{1, * \mathbb{D}}$, Andrew I. Yang ${ }^{1}$, Mario A. Cristancho ${ }^{2}$ and Gordon H. Baltuch ${ }^{1}$ \\ 1 Department of Neurosurgery, Pennsylvania Hospital, University of Pennsylvania, 800 Spruce St, \\ Philadelphia, PA 19107, USA; andrew.yang@pennmedicine.upenn.edu (A.I.Y.); \\ gordon.baltuch@pennmedicine.upenn.edu (G.H.B.) \\ 2 Department of Psychiatry, University of Pennsylvania, 3535 Market Street, Philadelphia, PA 19104, USA; \\ marioc@pennmedicine.upenn.edu \\ * Correspondence: Frederick.Hitti@uphs.upenn.edu; Tel.: +1-215-834-0444
}

Received: 21 July 2020; Accepted: 27 August 2020; Published: 30 August 2020

\begin{abstract}
Major depressive disorder (MDD) is a leading cause of disability and a significant cause of mortality worldwide. Approximately $30-40 \%$ of patients fail to achieve clinical remission with available pharmacological treatments, a clinical course termed treatment-resistant depression (TRD). Numerous studies have investigated deep brain stimulation (DBS) as a therapy for TRD. We performed a meta-analysis to determine efficacy and a meta-regression to compare stimulation targets. We identified and screened 1397 studies. We included 125 citations in the qualitative review and considered 26 for quantitative analysis. Only blinded studies that compared active DBS to sham stimulation $(\mathrm{k}=12)$ were included in the meta-analysis. The random-effects model supported the efficacy of DBS for TRD (standardized mean difference $=-0.75,<0$ favors active stimulation; $p=0.0001$ ). The meta-regression did not demonstrate a statistically significant difference between stimulation targets $(p=0.45)$. While enthusiasm for DBS treatment of TRD has been tempered by recent randomized trials, this meta-analysis reveals a significant effect of DBS for the treatment of TRD. Additionally, the majority of trials have demonstrated the safety and efficacy of DBS for this indication. Further trials are required to determine the optimal stimulation parameters and patient populations for which DBS would be effective. Particular attention to factors including electrode placement technique, patient selection, and long-term follow-up is essential for future trial design.
\end{abstract}

Keywords: deep brain stimulation; treatment-resistant depression; depression; meta-analysis; meta-regression; subcallosal cingulate gyrus; medial forebrain bundle; inferior thalamic peduncle; ventral capsule; ventral striatum

\section{Introduction}

Major depressive disorder (MDD) is one of the most common psychiatric diseases, and while a number of therapies are available, many patients remain symptomatic despite treatment [1,2]. Well-established treatment modalities for MDD include psychotherapy, medication, and electroconvulsive therapy (ECT) [3-9]. While ECT is efficacious for many patients resistant to medication and therapy, there are significant adverse effects associated with ECT, including cognitive and memory dysfunction [3]. Furthermore, there are patients who are refractory to multiple available therapies, including ECT. Patients who fail to improve following treatment with two or more therapies are considered to have treatment-resistant depression (TRD) [5,8,10-12]. Due to the considerable number of treatment non-remitters (30-40\% of patients with MDD), developing novel therapies for TRD represents a major unmet need. 
Deep brain stimulation (DBS) is a technique that uses implanted intracranial electrodes to modulate neural activity. It is currently a well-established, FDA-approved treatment for movement disorders such as Parkinson's disease (PD) and essential tremor (ET) [13,14]. In addition to movement disorders, DBS has been explored as a treatment modality for psychiatric conditions. Multiple human trials have explored the efficacy of DBS for TRD. Anatomic targets have included the ventral anterior limb of the internal capsule (vALIC) [15], ventral capsule/ventral striatum (VC/VS) [16], subcallosal cingulate (SCC) [17-22], inferior thalamic peduncle (ITP) [23], medial forebrain bundle (MFB) [24,25], and lateral habenula [26]. Reports regarding the efficacy of DBS for TRD have been mixed, with some studies demonstrating encouraging results, while others have shown a lack of efficacy relative to sham stimulation. To leverage all of the available data, we performed a meta-analysis to determine the efficacy of DBS for TRD. We then performed a meta-regression to compare stimulation targets. While prior meta-analyses have been undertaken [27-29], here we included only studies that compared active to sham stimulation in a blinded fashion. Furthermore, our analysis includes more recent studies.

\section{Methods}

\subsection{Search Strategy}

We used the PubMed database to identify studies investigating DBS for MDD and screened all studies for inclusion. We used the following search terms to identify relevant studies: ("deep brain stimulation"[MeSH Terms] OR ("deep"[All Fields] AND "brain"[All Fields] AND "stimulation"[All Fields]) OR "deep brain stimulation"[All Fields] OR "DBS"[All Fields]) AND ("depressive disorder"[MeSH Terms] OR ("depressive"[All Fields] AND “disorder"[All Fields]) OR "depressive disorder"[All Fields] OR "depression"[All Fields] OR "depression"[MeSH Terms]). All studies were considered, including studies written in other languages. The search was conducted on 10/16/2019, and the analysis followed the Preferred Reporting Items for Systematic reviews and Meta-Analyses (PRISMA) guidelines.

\subsection{Study Inclusion and Exclusion Criteria}

Only studies that investigated the efficacy of DBS for MDD were included. We excluded studies that utilized other therapies to treat MDD (e.g., ECT, epidural stimulation, vagal nerve stimulation, transcranial magnetic stimulation, or tDCS). We also excluded studies that investigated comorbid depression in the context of other disorders, such as epilepsy, dystonia, Tourette syndrome, anorexia nervosa, obsessive-compulsive disorder, schizophrenia, headache, ET, and PD. We excluded all non-human studies. Of the studies relevant to DBS as a treatment for MDD, we excluded case reports, non-systematic reviews, perspectives, commentaries, editorials, and opinions. We included the remainder of the studies for our qualitative review. For the quantitative meta-analysis, we only included studies in which sham stimulation was compared to active stimulation in a blinded fashion (either single- or double-blind). The clinical trial designs were varied and included both crossover and parallel studies.

\subsection{Data Extraction and Outcome Measures}

Our primary outcome was the efficacy of DBS as a treatment for depression as assessed by changes in the Hamilton Depression Rating Scale (HDRS) or Montgomery-Åsberg Depression Rating Scale (MADRS) scores. We compared sham stimulation scores to active stimulation scores. The data were extracted from tables when provided. If tables with the raw data were not provided, the WebPlotDigitizer tool was used to extract data from published graphs. We also extracted the number of patients, stimulation target, side effects of treatment, adverse events, study design, and depression rating scale used. 


\subsection{Statistical Methods}

Statistical analysis was conducted in $\mathrm{R}$ using the meta, metaphor, and dmetar packages. We followed the guide published by Harrer et al. to conduct the analysis [30]. A random-effects model was employed for the meta-analysis to account for differences in study populations. We used the DerSimonian-Laird estimator for $\tau^{2}$ (variance of true effect magnitude distributions), as it is the most widely used estimator. The studies included in the quantitative analysis used different depression rating scales. Therefore, we computed standardized mean differences so that the studies could be compared. We also calculated heterogeneity $\left(\mathrm{I}^{2}\right)$ of the studies in $\mathrm{R}$. The differential efficacies of the various stimulation targets were compared with mixed-effects meta-regression. $\mathrm{R}$ was used to generate funnel plots and conduct Egger's test. Means are presented with their corresponding standard deviations. A $p$-value $<0.05$ was considered statistically significant.

\section{Results}

We used fairly broad search terms (see Section 2) to ensure the inclusion of all studies relevant to the use of DBS as a therapy for depression. Our search identified 1397 studies, and all were screened for inclusion (Figure 1). We excluded 964 studies at the abstract/title level because these studies either did not use DBS as the therapeutic modality, examined depressive symptomatology in the context of other diseases, or were non-human animal studies. Of the remaining relevant studies, 308 were excluded because they were case reports, non-systematic reviews, perspectives, commentaries, editorials, or opinions. The remaining 125 studies were included in our qualitative review. We then screened these studies for inclusion in our quantitative meta-analysis. Twenty-six studies were candidates for inclusion at the abstract level. Thirteen studies were excluded because they did not compare active to sham stimulation [31-43], and one study was excluded as it included only three patients [44]. Therefore, 12 studies [15-25] (186 unique patients) were included in the meta-analysis and meta-regression (Table 1). The Raymaekers et al. study was analyzed as two separate studies, because this study included two anatomically distinct stimulation targets, and both targets were evaluated with blinded stimulation periods.

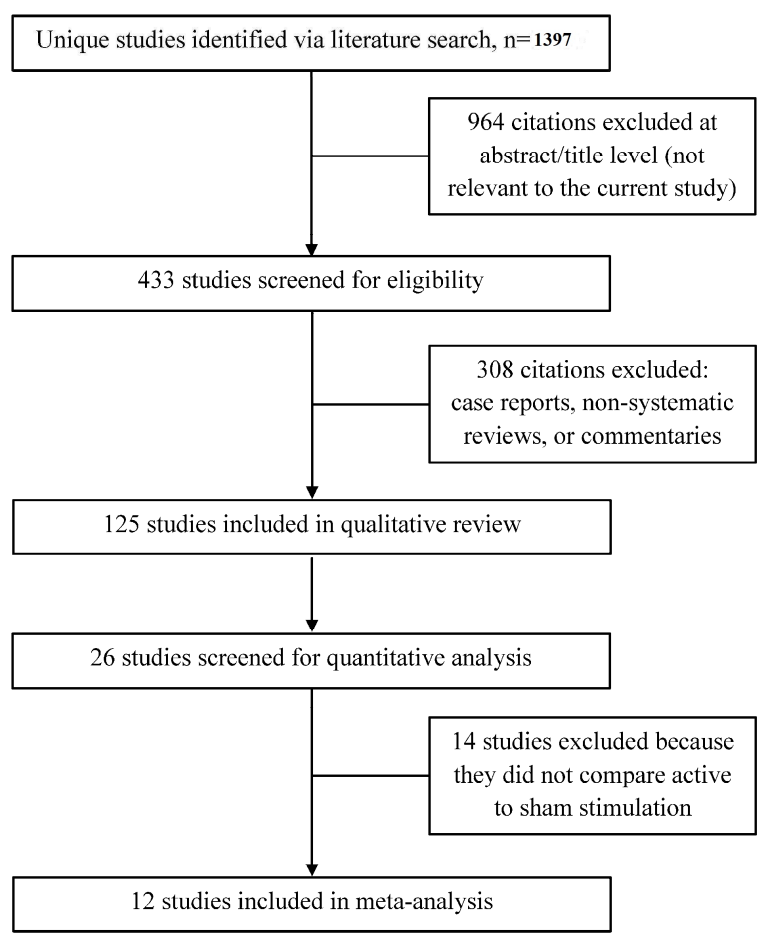

Figure 1. Flowchart of studies selected for inclusion in the qualitative review and quantitative meta-analysis. 
Table 1. Studies included in meta-analysis and meta-regression.

\begin{tabular}{cccc}
\hline Study & Location & N & Blinded Crossover \\
\hline Bergfeld et al. 2016 & vALIC & 16 & Yes \\
Coenen et al. 2019 & MFB & 16 & No \\
Dougherty et al. 2015 & VC/VS & 29 & No \\
Fenoy et al. 2018 & MFB & 6 & Yes \\
Holtzheimer et al. 2012 & SCC & 10 & Yes \\
Holtzheimer et al. 2017 & SCC & 85 & No \\
Merkl et al. 2013 & SCC & 6 & Yes \\
Merkl et al. 2018 & SCC & 4 & Yes* \\
Puigdemont et al. 2015 & SCC & 5 & Yes \\
Ramasubbu et al. 2013 & SCC & 4 & Yes \\
Raymaekers et al. 2017 & IC/BST & 5 & Yes \\
Raymaekers et al. 2017 & ITP & 5 & Yes
\end{tabular}

* Only half of the patients crossed over. IC/BST: internal capsule/bed nucleus of the stria terminalis; ITP: inferior thalamic peduncle; MFB: medial forebrain bundle; SCC: subcallosal cingulate; vALIC: ventral anterior limb of the internal capsule; VC/VS: ventral capsule/ventral striatum.

The studies included in the meta-analysis had varied trial designs (Table 1). Due to our inclusion criteria, all studies contained a period of blinded sham stimulation and blinded active stimulation. The duration of the active and sham stimulation periods, however, was heterogeneous. The average blinded stimulation duration was $7.5 \pm 6.6$ weeks. All studies contained an open-label period of long-term active stimulation following the blinded phases. These long-term data were not included in the meta-analysis, since the goal of the present study was to compare blinded active stimulation to blinded sham stimulation. The majority of the trials $(75 \%)$ were done in a crossover fashion (Table 1$)$. Thus, all of the patients in these studies received both active and sham stimulation in a blinded fashion. Importantly, these study designs allow for within-subject comparisons and may enhance statistical power.

Using a random-effects model, our meta-analysis revealed that active stimulation results in a greater decline in HDRS/MADRS scores relative to sham stimulation (standardized mean difference $(\mathrm{SMD})=-0.75 ;-1.13$ to $-0.36,95 \%$ confidence interval $(\mathrm{CI}) ; p$-value $=0.0001$; Figure 2$)$. There was moderate heterogeneity across studies $\left(\mathrm{I}^{2}=59 \%\right)$.

$\begin{array}{ll}\text { Source } & \text { SMD }(\mathbf{9 5 \%} \text { Cl) } \\ \text { Bergfeld et al. 2016 } & -1.16[-1.94 ;-0.39] \\ \text { Coenen et al. 2019 } & -0.88[-1.92 ; 0.15] \\ \text { Dougherty et al. 2015 } & 0.09[-0.64 ; 0.82] \\ \text { Fenoy et al. 2018 } & -2.99[-4.59 ;-1.38] \\ \text { Holtzheimer et al. 2012 } & -0.74[-1.44 ;-0.04] \\ \text { Holtzheimer et al. 2017 } & -0.25[-0.70 ; 0.20] \\ \text { Merkl et al. 2013 } & -0.42[-0.85 ; 0.01] \\ \text { Merkl et al. 2018 } & 0.56[-0.86 ; 1.98] \\ \text { Puigdemont et al. 2015 } & -1.40[-2.38 ;-0.42] \\ \text { Ramasubbu et al. 2013 } & -1.73[-2.84 ;-0.62] \\ \text { Raymaekers et al. 2017 (IC) } & -1.31[-3.53 ; 0.92] \\ \text { Raymaekers et al. 2017 (ITP) } & -0.56[-1.45 ; 0.33] \\ \text { Total } & -0.75[-1.13 ;-0.36] \\ \text { 95\% PI } & {[-1.91 ; 0.41]} \\ \text { Heterogeneity: } l^{2}=59 \% & \end{array}$

\section{Source}

Dougherty et al. 2015

Fenoy et al. 2018

Holtzheimer et al. 2017

Merkl et al. 2013

Merkl et al. 2018

Raymaekers et al. 2017 (ITP)

Heterogeneity: $I^{2}=59 \%$

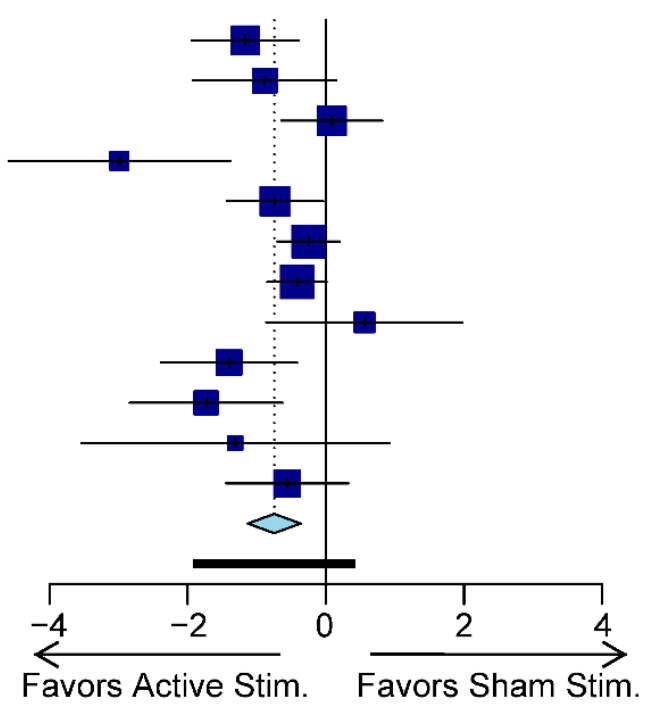

Standardized Mean Difference

Figure 2. Meta-analysis forest plot depicting changes in HDRS/MADRS scores with active stimulation compared to sham stimulation. CI: confidence interval; IC: internal capsule; ITP: inferior thalamic peduncle; SMD: standardized mean difference; PI: prediction interval. 
In addition to differences in study design, the studies also investigated the efficacy of DBS for TRD using different stimulation targets (Table 1$)$. The most common target was the SCC $(50 \%$ of studies), followed by the internal capsule (IC, 25\%), MFB (17\%), and ITP (8\%). While there were a limited number of studies, we utilized meta-regression to determine if the available data would reveal an optimal stimulation target. The meta-regression, however, did not demonstrate a statistically significant difference $(p=0.45)$ between stimulation targets (Figure 3).

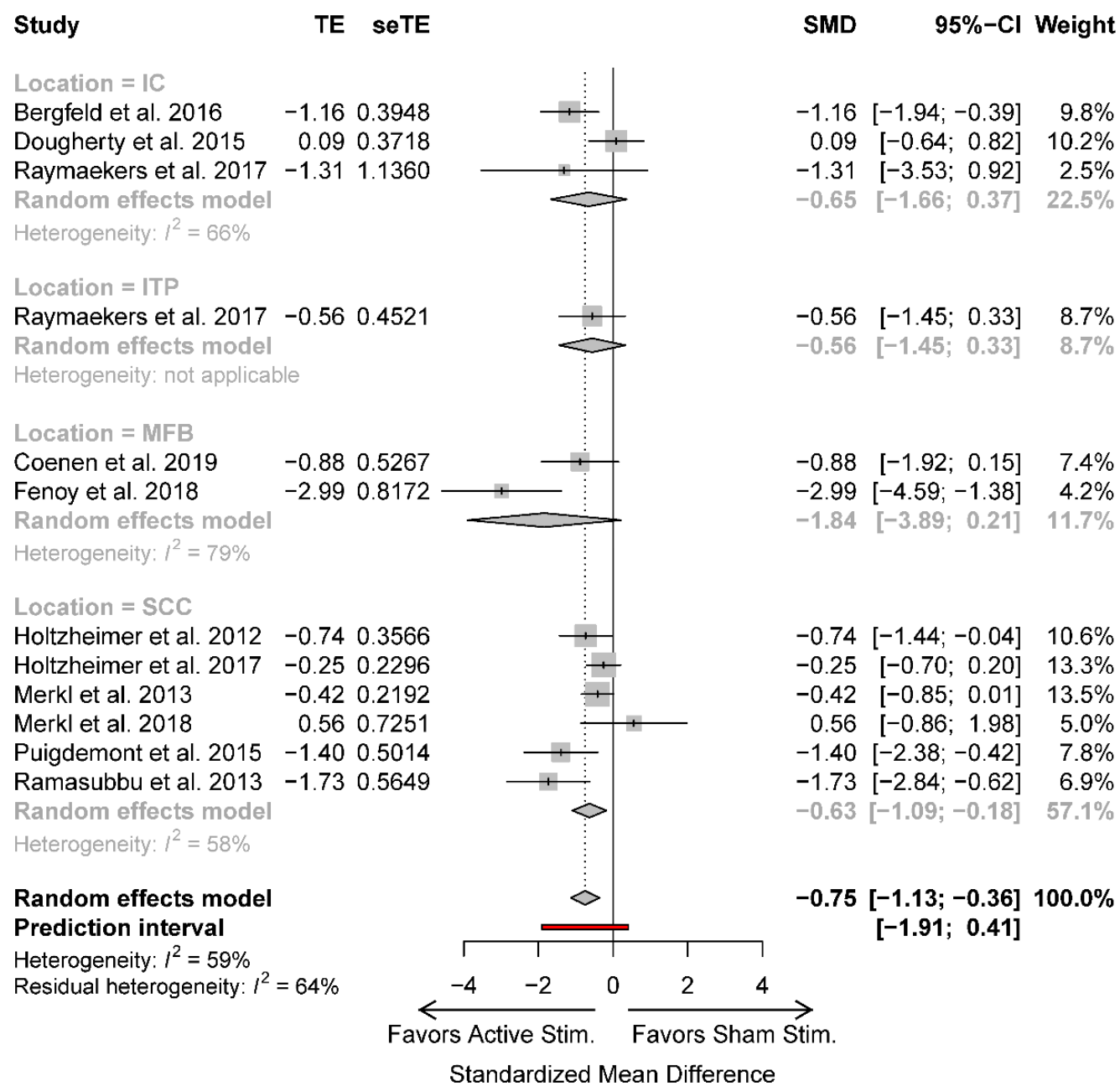

Figure 3. Meta-regression forest plot comparing various stimulation targets. CI: confidence interval; IC: internal capsule; ITP: inferior thalamic peduncle; MFB: medial forebrain bundle; SCC: subcallosal cingulate; SMD: standardized mean difference; TE: treatment effect; seTE: standard error of treatment effect.

Since the duration of stimulation during the blinded phase varied between studies, we performed another meta-regression to determine if there was an association between the duration of active stimulation and SMD. Our analysis did not reveal a significant effect of stimulation duration on SMD outcomes $(p=0.20)$.

Publication bias is an important concern when conducting a meta-analysis. We investigated for possible publication bias by first generating a funnel plot (Figure 4). We then tested for asymmetry of the funnel plot with Egger's test. The test revealed that there was no statistically significant asymmetry in the plot (intercept $-1.9 ; 95 \%$ CI $-3.864-0.056 ; p=0.07$ ), thus arguing against publication bias. Given the strong trend of Egger's test and the fact that one study (Fenoy et al. 2018) was a clear outlier, as depicted in the funnel plot, we re-analyzed the data with this outlier study excluded. Using a random-effects model, a meta-analysis of the pared data confirmed that active stimulation results in a 
greater decline in HDRS/MADRS scores relative to sham stimulation (SMD $=-0.62 ; 95 \% \mathrm{CI}-0.95$ to $-0.30 ; p=0.0002)$. Removing the outlier study decreased study heterogeneity $\left(\mathrm{I}^{2}=45 \%\right)$ and decreased the likelihood of publication bias as estimated by Egger's test (intercept $-1.3 ; 95 \%$ CI $-3.26-0.66$; $p=0.21$.

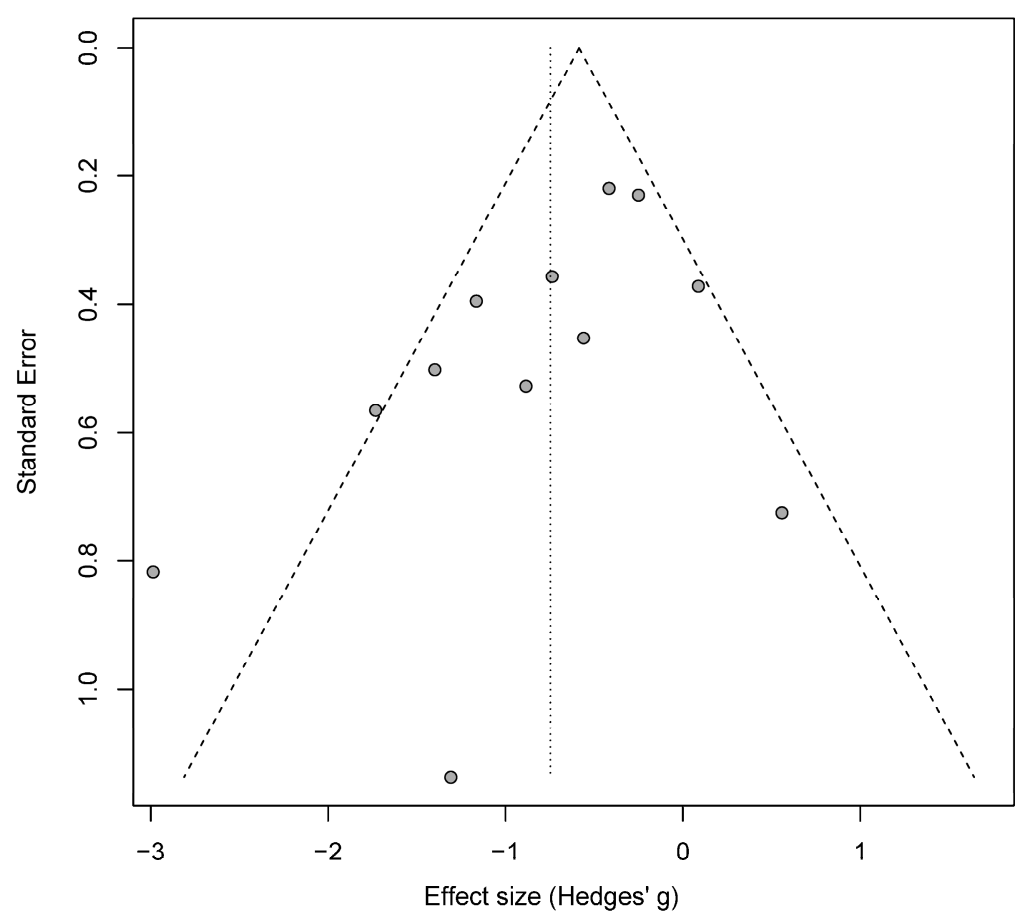

Figure 4. Funnel plot of studies included in the quantitative analysis.

We examined and compiled the adverse events reported in the studies included in the quantitative meta-analysis. The adverse events occurring in greater than $1 \%$ of patients are listed in Table 2, and the full list of adverse events in each study is detailed in Supplementary Table S1. The most common complaint was headache ( $26 \%$ of patients), followed by visual disturbances $(21 \%)$, worsening depression (16\%), sleep disturbances $(16 \%)$, and anxiety (14\%). All other adverse events were only seen in less than $10 \%$ of patients (Table 2). The authors of the original studies reported that the vast majority of adverse events were transient and were often resolved by stimulation parameter adjustment. The headaches were often postoperative and resolved a few days after surgery. A significant number of patients $(n=16,8 \%)$ expressed suicidal ideation, and a similar number of patients $(n=15,8 \%)$ attempted suicide. Completed suicides were rare. In two studies, one patient from each study who had no response to DBS committed suicide $[15,16]$. In one large study, there were two deaths by suicide in the control group during the open-label phase [17]. Finally, in another study, two patients committed suicide [23]. These suicides were deemed to be unrelated to DBS, because both patients had a history of suicide attempts and DBS did not appear to increase impulsivity [23]. 
Table 2. Adverse events.

\begin{tabular}{|c|c|c|}
\hline Adverse Event & Patients (N) & Patients (\%) \\
\hline Headache & 50 & 26 \\
\hline Blurred Vision/Diplopia & 41 & 21 \\
\hline Worsening depression & 31 & 16 \\
\hline Sleep Disturbances & 30 & 16 \\
\hline Anxiety & 26 & 14 \\
\hline Pain Around Neurostimulator & 17 & 9 \\
\hline Nausea & 16 & 8 \\
\hline Suicidal Ideation & 16 & 8 \\
\hline Pain Around Incisions & 16 & 8 \\
\hline Post-operative discomfort & 16 & 8 \\
\hline Suicide Attempt & 15 & 8 \\
\hline Device Infection & 15 & 8 \\
\hline Balance/Gait Problems & 13 & 7 \\
\hline Non-Specific Somatic Complaints & 12 & 6 \\
\hline $\begin{array}{c}\text { Pain/pulling sensation around } \\
\text { Extension Wires }\end{array}$ & 11 & 6 \\
\hline Other infections & 10 & 5 \\
\hline Agitation & 9 & 5 \\
\hline Paresthesias & 9 & 5 \\
\hline Restlessness & 8 & 4 \\
\hline Disinhibition/Impulsivity & 8 & 4 \\
\hline Hypomania & 8 & 4 \\
\hline Confusion/Cognitive impairment & 8 & 4 \\
\hline Swollen Eyes & 6 & 3 \\
\hline Excessive Sweating & 6 & 3 \\
\hline Memory Disturbance & 6 & 3 \\
\hline Weight Gain/hyperphagia & 6 & 3 \\
\hline Lethargy & 6 & 3 \\
\hline Abnormal Body Temperature & 5 & 3 \\
\hline Hypertension & 5 & 3 \\
\hline Postoperative Delirium & 4 & 2 \\
\hline Constipation & 4 & 2 \\
\hline Speech difficulties & 4 & 2 \\
\hline Panic attack & 4 & 2 \\
\hline Diarrhea & 4 & 2 \\
\hline Irritability & 4 & 2 \\
\hline Libido decrease/increase & 4 & 2 \\
\hline Increase in drug side effects & 4 & 2 \\
\hline Skin Disorder & 4 & 2 \\
\hline Neuralgia & 4 & 2 \\
\hline Drowsiness & 4 & 2 \\
\hline $\begin{array}{l}\text { Palpations Around } \\
\text { Neurostimulator }\end{array}$ & 3 & 2 \\
\hline Neck Pain & 3 & 2 \\
\hline Mania & 3 & 2 \\
\hline Hallucinations & 3 & 2 \\
\hline Palpitations & 3 & 2 \\
\hline Weakness & 3 & 2 \\
\hline Mood swings & 3 & 2 \\
\hline $\begin{array}{l}\text { Difficulty voiding/urinary } \\
\text { retention }\end{array}$ & 3 & 2 \\
\hline Back pain & 3 & 2 \\
\hline Electrode revision & 3 & 2 \\
\hline Elective hospitalization & 3 & 2 \\
\hline
\end{tabular}




\section{Discussion}

MDD is a very prevalent neuropsychiatric condition. Although there are a number of existing treatment modalities, many patients remain symptomatic despite adequate treatment protocols. There is an urgent need for additional treatment options for TRD, since it is a significant source of morbidity and mortality.

Pathological neural activity (either hyperactivity or hypoactivity) may lead to neurological or psychiatric disease, and non-pharmacological neuromodulatory techniques may be used to ameliorate these conditions. DBS is a neuromodulatory approach that is an FDA-approved treatment for movement disorders, so multiple investigators have trialed DBS as a therapy for TRD. Initial open-label reports regarding the efficacy of DBS for TRD were encouraging [36,45], and subsequently, multiple randomized trials were initiated and completed [16,17]. The large-scale trials, however, did not reveal a significant difference between the control and treatment groups. A number of reasons have been posited to explain these negative results, including choice of stimulation target, electrode placement technique, patient selection, and short-term follow-up of patients [43,46-52].

Due to the discrepancy between earlier reports and larger trials, we undertook a meta-analysis to investigate the efficacy of DBS for TRD. In agreement with prior analyses [27-29], we found a significant effect of DBS on TRD. Specifically, active stimulation was associated with an improvement in depression scores relative to sham stimulation. The effect size of this treatment is medium to large, as indicated by the SMD of -0.75 [53]. This effect size is much larger than the small effect sizes $(\sim 0.3)$ seen with pharmacologic antidepressant treatment of patients with MDD [54]. Our findings extend those of prior analyses by including all currently available studies and by only including blinded studies that utilized a trial design in which active stimulation was compared to sham stimulation. Importantly, analyzing the data in this manner allows for the control of placebo effects. While some patients are able to detect active stimulation due to side effects such as visual disturbances, these effects are largely absent with a stimulation parameter adjustment [24,25]. With most studies including an optimization phase prior to the blinded assessments, it is reasonable to propose that comparing active stimulation to sham stimulation controls for placebo effects.

We conducted a meta-regression to determine if the data would reveal an optimal stimulation target. Due to the limited number of available studies, our analysis did not demonstrate an optimal target. With further research, the answer to this question may be elucidated in the future; however, a significant limitation is the heterogeneous nature of MDD neurobiology (i.e., symptoms of depression as a common manifestation of multiple brain functional abnormalities). It may be that instead of one optimal stimulation target for all patients, the optimal stimulation target varies across individuals [46,55-58].

As with any therapy, there is a risk of publication bias since studies with positive results and large effect sizes are more likely to be published than studies with small effect sizes or negative results [59]. To investigate publication bias in DBS for depression, we plotted the studies in a funnel plot and used Egger's test to assess for asymmetry. We did not find evidence of publication bias in this series of studies.

DBS is a well-tolerated treatment for movement disorders, but it is important to critically evaluate potential side effects of DBS for depression. The thoroughness of adverse event reporting varied between the studies. Nonetheless, the majority of adverse events were transient. Furthermore, many side effects were relieved by a stimulation parameter adjustment, as is seen with DBS for movement disorders. Patients with MDD are at significant risk for suicide, and patients with TRD have an even higher risk of suicide $[60,61]$. Currently available data do not demonstrate an increased risk of suicide with DBS, since suicide was rare in these studies and occurred at a lower rate than in patients with severe MDD not receiving DBS [62]. Moreover, the completed suicides occurred in non-responders or were deemed unrelated to DBS. As an invasive therapy, DBS may be perceived by patients as a "last resort" for recovery. Therefore, non-responders may represent a particularly high-risk group for suicide. Psychoeducation and adequate discussion of post DBS treatment options to reframe those 
perceptions may decrease the risk of suicide. In summary, published trials have demonstrated the safety of DBS for TRD.

While the results of this meta-analysis are encouraging, additional large-scale clinical trials demonstrating the efficacy of DBS for TRD are essential. Crucial to these efforts will be careful consideration of future trial design [24,63]. The large-scale clinical trials of DBS for TRD conducted to date have utilized a parallel trial design, whereas many of the smaller trials employed a crossover design (Table 1). Given the negative outcomes of the large-scale trials, a crossover design may be optimal to investigate the efficacy of DBS for TRD. As a therapy, DBS is unique in that sham stimulation and active stimulation may be compared within individuals, thereby facilitating crossover trial design. Crossover studies require fewer patients to achieve significance, so this design optimizes statistical power [64]. Some studies have used customized trial designs with a variable optimization period $[15,65]$. Ensuring proper optimization prior to randomization may be necessary to determine the efficacy of DBS for TRD. Another important factor in trial design is the length of time that the patient undergoes therapy. Long-term open-label studies have demonstrated that the efficacy of DBS for TRD improves over time, so longer trials may be necessary $[17,18,38,66,67]$. Finally, depression severity waxes and wanes throughout a patient's disease course. Therefore, trial designs that compare groups at specific time points may not be optimal. Integrating scores over predefined time periods may enhance outcome assessment.

In addition to trial design, proper electrode targeting is important for the efficacy of DBS for the treatment of depression. Instead of targeting brain nuclei, as is routinely done, targeting fiber tracts using patient-specific tractography may be important for therapeutic efficacy $[49-52,58,68]$. Furthermore, stereotactic accuracy of electrode placement is essential. For example, intraoperative phenomena, such as brain shift, should be accounted for [48]. Patient selection is also a critical consideration for future studies. The available data have demonstrated that there is a subgroup of patients that respond to this therapy and a subgroup that does not. Determining patient-specific factors (e.g., anatomical or symptom-based) that predict response to DBS for TRD may enable targeted selection of patients for whom DBS would be therapeutic [43,69-75]. These patient-specific factors could then be used as study inclusion criteria to enhance the probability of study success.

\section{Conclusions}

While enthusiasm for DBS as a therapy for TRD has been tempered by recent randomized trials, this meta-analysis reveals that active stimulation significantly ameliorates depression in patients with TRD. The meta-regression did not reveal an optimal stimulation target to treat depression due to the small size and number of available studies, and also likely due to the heterogeneous nature of this condition's neurobiology. Additional trials are needed to determine optimal stimulation targets. Further studies are also required to establish the patient populations for whom DBS would be effective. Particular attention to factors that include electrode placement technique, patient selection, and long-term observation is essential for future trial design.

Supplementary Materials: The following are available online at http://www.mdpi.com/2077-0383/9/9/2796/s1, Table S1: Complete list of adverse events.

Author Contributions: Conceptualization, F.L.H. and G.H.B.; methodology, F.L.H.; validation, F.L.H., A.I.Y., M.A.C., G.H.B.; formal analysis, F.L.H and A.I.Y; investigation, F.L.H.; data curation, F.L.H.; writing-Original draft preparation, F.L.H. and A.I.Y.; writing-Review and editing, F.L.H., A.I.Y., M.A.C., G.H.B.; visualization, F.L.H.; supervision, G.H.B.; project administration, G.H.B. All authors have read and agreed to the published version of the manuscript.

Funding: This research received no external funding.

Conflicts of Interest: The authors declare no conflict of interest. 


\section{References}

1. Ferrari, A.J.; Charlson, F.J.; Norman, R.E.; Patten, S.B.; Freedman, G.; Murray, C.J.L.; Vos, T.; Whiteford, H.A. Burden of Depressive Disorders by Country, Sex, Age, and Year: Findings from the Global Burden of Disease Study 2010. PLoS Med. 2013, 10, e1001547. [CrossRef] [PubMed]

2. Steel, Z.; Marnane, C.; Iranpour, C.; Chey, T.; Jackson, J.W.; Patel, V.; Silove, D. The global prevalence of common mental disorders: A systematic review and meta-analysis 1980-2013. Int. J. Epidemiol. 2014, 43, 476-493. [CrossRef] [PubMed]

3. Bailine, S.H.; Rifkin, A.; Kayne, E.; Selzer, J.A.; Vital-Herne, J.; Blieka, M.; Pollack, S. Comparison of Bifrontal and Bitemporal ECT for Major Depression. Am. J. Psychiatry 2000, 157, 121-123. [CrossRef] [PubMed]

4. Fava, M.; Rush, A.J.; Wisniewski, S.R.; Nierenberg, A.A.; Alpert, J.E.; McGrath, P.J.; Thase, M.E.; Warden, D.; Biggs, M.; Luther, J.F.; et al. A comparison of mirtazapine and nortriptyline following two consecutive failed medication treatments for depressed outpatients: A STAR*D report. Am. J. Psychiatry 2006, 163, 1161-1172. [CrossRef]

5. Hollon, S.D.; Jarrett, R.B.; Nierenberg, A.A.; Thase, M.E.; Trivedi, M.; Rush, A.J. Psychotherapy and Medication in the Treatment of Adult and Geriatric Depression: Which Monotherapy or Combined Treatment? J. Clin. Psychiatry 2005, 66, 455-468. [CrossRef]

6. Nierenberg, A.A.; Fava, M.; Trivedi, M.H.; Wisniewski, S.R.; Thase, M.E.; McGrath, P.J.; Alpert, J.E.; Warden, D.; Luther, J.F.; Niederehe, G.; et al. A Comparison of Lithium and T 3 Augmentation Following Two Failed Medication Treatments for Depression: A STAR*D Report. Am. J. Psychiatry 2006, 163, 1519-1530. [CrossRef]

7. Rush, A.J.; Trivedi, M.H.; Wisniewski, S.R.; Stewart, J.W.; Nierenberg, A.A.; Thase, M.E.; Ritz, L.; Biggs, M.M.; Warden, D.; Luther, J.F.; et al. Bupropion-SR, sertraline, or venlafaxine-XR after failure of SSRIs for depression. N. Engl. J. Med. 2006, 354, 1231-1242. [CrossRef]

8. Thase, M.E.; Friedman, E.S.; Biggs, M.M.; Wisniewski, S.R.; Trivedi, M.H.; Luther, J.F.; Fava, M.; Nierenberg, A.A.; McGrath, P.J.; Warden, D.; et al. Cognitive Therapy Versus Medication in Augmentation and Switch Strategies as Second-Step Treatments: A STARD Report. Am. J. Psychiatry 2007, 164, 739-752. [CrossRef]

9. Trivedi, M.H.; Rush, A.J.; Wisniewski, S.R.; Nierenberg, A.A.; Warden, D.; Ritz, L.; Norquist, G.; Howland, R.H.; Lebowitz, B.; McGrath, P.J.; et al. Evaluation of Outcomes With Citalopram for Depression Using Measurement-Based Care in STAR*D: Implications for Clinical Practice. Am. J. Psychiatry 2006, 163, 28-40. [CrossRef]

10. Souery, D.; Papakostas, G.I.; Trivedi, M.H. Treatment-resistant depression. J. Clin. Psychiatry 2006, 67 (Suppl. 6), 16-22.

11. Greden, J.F. The burden of disease for treatment-resistant depression. J. Clin. Psychiatry 2001, 62 (Suppl. 16), $26-31$.

12. Taipale, H.; Reutfors, J.; Tanskanen, A.; Brandt, L.; Tiihonen, J.; DiBernardo, A.; Mittendorfer-Rutz, E.; Brenner, P. Risk and risk factors for disability pension among patients with treatment resistant depression- a matched cohort study. BMC Psychiatry 2020, 20, 232. [CrossRef] [PubMed]

13. Hitti, F.L.; Ramayya, A.G.; McShane, B.J.; Yang, A.I.; Vaughan, K.A.; Baltuch, G.H. Long-term outcomes following deep brain stimulation for Parkinson's disease. J. Neurosurg. 2019. [CrossRef] [PubMed]

14. Miocinovic, S.; Somayajula, S.; Chitnis, S.; Vitek, J.L. History, Applications, and Mechanisms of Deep Brain Stimulation. JAMA Neurol. 2013, 70, 163-171. [CrossRef] [PubMed]

15. Bergfeld, I.O.; Mantione, M.; Hoogendoorn, M.L.C.; Ruhe, H.G.; Notten, P.; van Laarhoven, J.; Visser, I.; Figee, M.; de Kwaasteniet, B.P.; Horst, F.; et al. Deep Brain Stimulation of the Ventral Anterior Limb of the Internal Capsule for Treatment-Resistant Depression: A Randomized Clinical Trial. JAMA Psychiatry 2016, 73, 456-464. [CrossRef] [PubMed]

16. Dougherty, D.D.; Rezai, A.R.; Carpenter, L.L.; Howland, R.H.; Bhati, M.T.; O’Reardon, J.P.; Eskandar, E.N.; Baltuch, G.H.; Machado, A.D.; Kondziolka, D.; et al. A Randomized Sham-Controlled Trial of Deep Brain Stimulation of the Ventral Capsule/Ventral Striatum for Chronic Treatment-Resistant Depression. Biol. Psychiatry 2015, 78, 240-248. [CrossRef] 
17. Holtzheimer, P.E.; Husain, M.M.; Lisanby, S.H.; Taylor, S.F.; Whitworth, L.A.; McClintock, S.; Slavin, K.V.; Berman, J.; McKhann, G.M.; Patil, P.G.; et al. Subcallosal cingulate deep brain stimulation for treatment-resistant depression: A multisite, randomised, sham-controlled trial. Lancet Psychiatry 2017, 4, 839-849. [CrossRef]

18. Holtzheimer, P.E.; Kelley, M.E.; Gross, R.E.; Filkowski, M.M.; Garlow, S.J.; Barrocas, A.; Wint, D.; Craighead, M.C.; Kozarsky, J.; Chismar, R.; et al. Subcallosal cingulate deep brain stimulation for treatment-resistant unipolar and bipolar depression. Arch. Gen. Psychiatry 2012, 69, 150-158. [CrossRef]

19. Merkl, A.; Schneider, G.-H.; Schonecker, T.; Aust, S.; Kuhl, K.-P.; Kupsch, A.; Kuhn, A.A.; Bajbouj, M. Antidepressant effects after short-term and chronic stimulation of the subgenual cingulate gyrus in treatment-resistant depression. Exp. Neurol. 2013, 249, 160-168. [CrossRef]

20. Merkl, A.; Aust, S.; Schneider, G.-H.; Visser-Vandewalle, V.; Horn, A.; Kuhn, A.A.; Kuhn, J.; Bajbouj, M. Deep brain stimulation of the subcallosal cingulate gyrus in patients with treatment-resistant depression: A double-blinded randomized controlled study and long-term follow-up in eight patients. J. Affect. Disord. 2018, 227, 521-529. [CrossRef]

21. Puigdemont, D.; Portella, M.; Perez-Egea, R.; Molet, J.; Gironell, A.; de Diego-Adelino, J.; Martin, A.; Rodriguez, R.; Alvarez, E.; Artigas, F.; et al. A randomized double-blind crossover trial of deep brain stimulation of the subcallosal cingulate gyrus in patients with treatment-resistant depression: A pilot study of relapse prevention. J. Psychiatry Neurosci. JPN 2015, 40, 224-231. [CrossRef] [PubMed]

22. Ramasubbu, R.; Anderson, S.; Haffenden, A.; Chavda, S.; Kiss, Z.H.T. Double-blind optimization of subcallosal cingulate deep brain stimulation for treatment-resistant depression: A pilot study. J. Psychiatry Neurosci. JPN 2013, 38, 325-332. [CrossRef] [PubMed]

23. Raymaekers, S.; Luyten, L.; Bervoets, C.; Gabriels, L.; Nuttin, B. Deep brain stimulation for treatment-resistant major depressive disorder: A comparison of two targets and long-term follow-up. Transl. Psychiatry 2017, 7, e1251. [CrossRef] [PubMed]

24. Coenen, V.A.; Bewernick, B.H.; Kayser, S.; Kilian, H.; Bostrom, J.; Greschus, S.; Hurlemann, R.; Klein, M.E.; Spanier, S.; Sajonz, B.; et al. Superolateral medial forebrain bundle deep brain stimulation in major depression: A gateway trial. Neuropsychopharmacol. Off. Publ. Am. Coll. Neuropsychopharmacol. 2019, 44, 1224-1232. [CrossRef]

25. Fenoy, A.J.; Schulz, P.E.; Selvaraj, S.; Burrows, C.L.; Zunta-Soares, G.; Durkin, K.; Zanotti-Fregonara, P.; Quevedo, J.; Soares, J.C. A longitudinal study on deep brain stimulation of the medial forebrain bundle for treatment-resistant depression. Transl. Psychiatry 2018, 8, 111. [CrossRef] [PubMed]

26. Sartorius, A.; Kiening, K.L.; Kirsch, P.; von Gall, C.C.; Haberkorn, U.; Unterberg, A.W.; Henn, F.A.; Meyer-Lindenberg, A. Remission of Major Depression Under Deep Brain Stimulation of the Lateral Habenula in a Therapy-Refractory Patient. Biol. Psychiatry 2010, 67, e9-e11. [CrossRef]

27. Zhou, C.; Zhang, H.; Qin, Y.; Tian, T.; Xu, B.; Chen, J.; Zhou, X.; Zeng, L.; Fang, L.; Qi, X.; et al. A systematic review and meta-analysis of deep brain stimulation in treatment-resistant depression. Prog. Neuropsychopharmacol. Biol. Psychiatry 2018, 82, 224-232. [CrossRef]

28. Kisely, S.; Li, A.; Warren, N.; Siskind, D. A systematic review and meta-analysis of deep brain stimulation for depression. Depress. Anxiety 2018, 35, 468-480. [CrossRef]

29. Berlim, M.T.; McGirr, A.; Van den Eynde, F.; Fleck, M.P.A.; Giacobbe, P. Effectiveness and acceptability of deep brain stimulation (DBS) of the subgenual cingulate cortex for treatment-resistant depression: A systematic review and exploratory meta-analysis. J. Affect. Disord. 2014, 159, 31-38. [CrossRef]

30. Harrer, M.; Cuijpers, P.; Furukawa, T.; Ebert, D. Doing Meta-Analysis in R: A Hands-on Guide. Available online: https://bookdown.org/MathiasHarrer/Doing_Meta_Analysis_in_R/ (accessed on 26 June 2020).

31. Lozano, A.M.; Mayberg, H.S.; Giacobbe, P.; Hamani, C.; Craddock, R.C.; Kennedy, S.H. Subcallosal cingulate gyrus deep brain stimulation for treatment-resistant depression. Biol. Psychiatry 2008, 64, 461-467. [CrossRef]

32. Lozano, A.M.; Giacobbe, P.; Hamani, C.; Rizvi, S.J.; Kennedy, S.H.; Kolivakis, T.T.; Debonnel, G.; Sadikot, A.F.; Lam, R.W.; Howard, A.K.; et al. A multicenter pilot study of subcallosal cingulate area deep brain stimulation for treatment-resistant depression. J. Neurosurg. 2012, 116, 315-322. [CrossRef] [PubMed]

33. Puigdemont, D.; Perez-Egea, R.; Portella, M.J.; Molet, J.; de Diego-Adelino, J.; Gironell, A.; Radua, J.; Gomez-Anson, B.; Rodriguez, R.; Serra, M.; et al. Deep brain stimulation of the subcallosal cingulate gyrus: Further evidence in treatment-resistant major depression. Int. J. Neuropsychopharmacol. 2012, 15, 121-133. [CrossRef] [PubMed] 
34. Bewernick, B.H.; Hurlemann, R.; Matusch, A.; Kayser, S.; Grubert, C.; Hadrysiewicz, B.; Axmacher, N.; Lemke, M.; Cooper-Mahkorn, D.; Cohen, M.X.; et al. Nucleus accumbens deep brain stimulation decreases ratings of depression and anxiety in treatment-resistant depression. Biol. Psychiatry 2010, 67, 110-116. [CrossRef] [PubMed]

35. Millet, B.; Jaafari, N.; Polosan, M.; Baup, N.; Giordana, B.; Haegelen, C.; Chabardes, S.; Fontaine, D.; Devaux, B.; Yelnik, J.; et al. Limbic versus cognitive target for deep brain stimulation in treatment-resistant depression: Accumbens more promising than caudate. Eur. Neuropsychopharmacol. J. Eur. Coll. Neuropsychopharmacol. 2014, 24, 1229-1239. [CrossRef]

36. Malone, D.A.J.; Dougherty, D.D.; Rezai, A.R.; Carpenter, L.L.; Friehs, G.M.; Eskandar, E.N.; Rauch, S.L.; Rasmussen, S.A.; Machado, A.G.; Kubu, C.S.; et al. Deep brain stimulation of the ventral capsule/ventral striatum for treatment-resistant depression. Biol. Psychiatry 2009, 65, 267-275. [CrossRef]

37. Bewernick, B.H.; Kayser, S.; Gippert, S.M.; Switala, C.; Coenen, V.A.; Schlaepfer, T.E. Deep brain stimulation to the medial forebrain bundle for depression- long-term outcomes and a novel data analysis strategy. Brain Stimulat. 2017, 10, 664-671. [CrossRef]

38. Crowell, A.L.; Riva-Posse, P.; Holtzheimer, P.E.; Garlow, S.J.; Kelley, M.E.; Gross, R.E.; Denison, L.; Quinn, S.; Mayberg, H.S. Long-Term Outcomes of Subcallosal Cingulate Deep Brain Stimulation for Treatment-Resistant Depression. Am. J. Psychiatry 2019. [CrossRef]

39. Schlaepfer, T.E.; Bewernick, B.H.; Kayser, S.; Madler, B.; Coenen, V.A. Rapid effects of deep brain stimulation for treatment-resistant major depression. Biol. Psychiatry 2013, 73, 1204-1212. [CrossRef]

40. Bewernick, B.H.; Kayser, S.; Sturm, V.; Schlaepfer, T.E. Long-term effects of nucleus accumbens deep brain stimulation in treatment-resistant depression: Evidence for sustained efficacy. Neuropsychopharmacol. Off. Publ. Am. Coll. Neuropsychopharmacol. 2012, 37, 1975-1985. [CrossRef]

41. Eitan, R.; Fontaine, D.; Benoit, M.; Giordana, C.; Darmon, N.; Israel, Z.; Linesky, E.; Arkadir, D.; Ben-Naim, S.; Iserlles, M.; et al. One year double blind study of high vs low frequency subcallosal cingulate stimulation for depression. J. Psychiatr. Res. 2018, 96, 124-134. [CrossRef]

42. Accolla, E.A.; Aust, S.; Merkl, A.; Schneider, G.-H.; Kuhn, A.A.; Bajbouj, M.; Draganski, B. Deep brain stimulation of the posterior gyrus rectus region for treatment resistant depression. J. Affect. Disord. 2016, 194, 33-37. [CrossRef] [PubMed]

43. Sankar, T.; Chakravarty, M.M.; Jawa, N.; Li, S.X.; Giacobbe, P.; Kennedy, S.H.; Rizvi, S.J.; Mayberg, H.S.; Hamani, C.; Lozano, A.M. Neuroanatomical predictors of response to subcallosal cingulate deep brain stimulation for treatment-resistant depression. J. Psychiatry Neurosci. JPN 2019, 44, 1-10. [CrossRef] [PubMed]

44. Schlaepfer, T.E.; Cohen, M.X.; Frick, C.; Kosel, M.; Brodesser, D.; Axmacher, N.; Joe, A.Y.; Kreft, M.; Lenartz, D.; Sturm, V. Deep Brain Stimulation to Reward Circuitry Alleviates Anhedonia in Refractory Major Depression. Neuropsychopharmacology 2008, 33, 368-377. [CrossRef] [PubMed]

45. Mayberg, H.S.; Lozano, A.M.; Voon, V.; McNeely, H.E.; Seminowicz, D.; Hamani, C.; Schwalb, J.M.; Kennedy, S.H. Deep brain stimulation for treatment-resistant depression. Neuron 2005, 45, 651-660. [CrossRef]

46. Dandekar, M.P.; Fenoy, A.J.; Carvalho, A.F.; Soares, J.C.; Quevedo, J. Deep brain stimulation for treatment-resistant depression: An integrative review of preclinical and clinical findings and translational implications. Mol. Psychiatry 2018, 23, 1094-1112. [CrossRef]

47. Fins, J.J.; Kubu, C.S.; Mayberg, H.S.; Merkel, R.; Nuttin, B.; Schlaepfer, T.E. Being open minded about neuromodulation trials: Finding success in our "failures". Brain Stimulat. 2017, 10, 181-186. [CrossRef]

48. Choi, K.S.; Noecker, A.M.; Riva-Posse, P.; Rajendra, J.K.; Gross, R.E.; Mayberg, H.S.; McIntyre, C.C. Impact of brain shift on subcallosal cingulate deep brain stimulation. Brain Stimulat. 2018, 11, 445-453. [CrossRef]

49. Noecker, A.M.; Choi, K.S.; Riva-Posse, P.; Gross, R.E.; Mayberg, H.S.; McIntyre, C.C. StimVision Software: Examples and Applications in Subcallosal Cingulate Deep Brain Stimulation for Depression. Neuromodulation J. Int. Neuromodulation Soc. 2018, 21, 191-196. [CrossRef]

50. Riva-Posse, P.; Choi, K.S.; Holtzheimer, P.E.; Crowell, A.L.; Garlow, S.J.; Rajendra, J.K.; McIntyre, C.C.; Gross, R.E.; Mayberg, H.S. A connectomic approach for subcallosal cingulate deep brain stimulation surgery: Prospective targeting in treatment-resistant depression. Mol. Psychiatry 2018, 23, 843-849. [CrossRef]

51. Tsolaki, E.; Espinoza, R.; Pouratian, N. Using probabilistic tractography to target the subcallosal cingulate cortex in patients with treatment resistant depression. Psychiatry Res. Neuroimaging 2017, 261, 72-74. [CrossRef] 
52. Coenen, V.A.; Sajonz, B.; Reisert, M.; Bostroem, J.; Bewernick, B.; Urbach, H.; Jenkner, C.; Reinacher, P.C.; Schlaepfer, T.E.; Madler, B. Tractography-assisted deep brain stimulation of the superolateral branch of the medial forebrain bundle (slMFB DBS) in major depression. NeuroImage Clin. 2018, 20, 580-593. [CrossRef] [PubMed]

53. Faraone, S.V. Interpreting Estimates of Treatment Effects. Pharm. Ther. 2008, 33, 700-711.

54. Locher, C.; Koechlin, H.; Zion, S.R.; Werner, C.; Pine, D.S.; Kirsch, I.; Kessler, R.C.; Kossowsky, J. Efficacy and Safety of Selective Serotonin Reuptake Inhibitors, Serotonin-Norepinephrine Reuptake Inhibitors, and Placebo for Common Psychiatric Disorders Among Children and Adolescents. JAMA Psychiatry 2017, 74, 1011-1020. [CrossRef] [PubMed]

55. Drobisz, D.; Damborska, A. Deep brain stimulation targets for treating depression. Behav. Brain Res. 2019, 359, 266-273. [CrossRef]

56. Guo, C.C.; Hyett, M.P.; Nguyen, V.T.; Parker, G.B.; Breakspear, M.J. Distinct neurobiological signatures of brain connectivity in depression subtypes during natural viewing of emotionally salient films. Psychol. Med. 2016, 46, 1535-1545. [CrossRef]

57. Williams, N.R.; Okun, M.S. Deep brain stimulation (DBS) at the interface of neurology and psychiatry. J. Clin. Investig. 2013, 123, 4546-4556. [CrossRef]

58. Coenen, V.A.; Schlaepfer, T.E.; Reinacher, P.C.; Mast, H.; Urbach, H.; Reisert, M. Machine learning-aided personalized DTI tractographic planning for deep brain stimulation of the superolateral medial forebrain bundle using HAMLET. Acta Neurochir. (Wien) 2019, 161, 1559-1569. [CrossRef]

59. van Aert, R.C.M.; Wicherts, J.M.; van Assen, M.A.L.M. Publication bias examined in meta-analyses from psychology and medicine: A meta-meta-analysis. PLoS ONE 2019, 14, e0215052. [CrossRef]

60. Bergfeld, I.O.; Mantione, M.; Figee, M.; Schuurman, P.R.; Lok, A.; Denys, D. Treatment-resistant depression and suicidality. J. Affect. Disord. 2018, 235, 362-367. [CrossRef]

61. Seo, H.-J.; Jung, Y.-E.; Jeong, S.; Kim, J.-B.; Lee, M.-S.; Kim, J.-M.; Yim, H.W.; Jun, T.-Y. Persistence and resolution of suicidal ideation during treatment of depression in patients with significant suicidality at the beginning of treatment: The CRESCEND study. J. Affect. Disord. 2014, 155, 208-215. [CrossRef]

62. Wulsin, L.R.; Vaillant, G.E.; Wells, V.E. A systematic review of the mortality of depression. Psychosom. Med. 1999, 61, 6-17. [CrossRef] [PubMed]

63. Bari, A.A.; Mikell, C.B.; Abosch, A.; Ben-Haim, S.; Buchanan, R.J.; Burton, A.W.; Carcieri, S.; Cosgrove, G.R.; D'Haese, P.-F.; Daskalakis, Z.J.; et al. Charting the road forward in psychiatric neurosurgery: Proceedings of the 2016 American Society for Stereotactic and Functional Neurosurgery workshop on neuromodulation for psychiatric disorders. J. Neurol. Neurosurg. Psychiatry 2018, 89, 886-896. [CrossRef] [PubMed]

64. Jones, B.; Lewis, J.A. The case for cross-over trials in phase III. Stat. Med. 1995, 14, 1025-1038. [CrossRef] [PubMed]

65. Mayberg, H.S.; Riva-Posse, P.; Crowell, A.L. Deep Brain Stimulation for Depression: Keeping an Eye on a Moving Target. JAMA Psychiatry 2016, 73, 439-440. [CrossRef]

66. Kennedy, S.H.; Giacobbe, P.; Rizvi, S.J.; Placenza, F.M.; Nishikawa, Y.; Mayberg, H.S.; Lozano, A.M. Deep brain stimulation for treatment-resistant depression: Follow-up after 3 to 6 years. Am. J. Psychiatry 2011, 168, 502-510. [CrossRef]

67. van der Wal, J.M.; Bergfeld, I.O.; Lok, A.; Mantione, M.; Figee, M.; Notten, P.; Beute, G.; Horst, F.; van den Munckhof, P.; Schuurman, P.R.; et al. Long-term deep brain stimulation of the ventral anterior limb of the internal capsule for treatment-resistant depression. J. Neurol. Neurosurg. Psychiatry 2020, 91, 189-195. [CrossRef]

68. Bhatia, K.D.; Henderson, L.; Ramsey-Stewart, G.; May, J. Diffusion tensor imaging to aid subgenual cingulum target selection for deep brain stimulation in depression. Stereotact. Funct. Neurosurg. 2012, 90, 225-232. [CrossRef]

69. Coenen, V.A.; Schlaepfer, T.E.; Bewernick, B.; Kilian, H.; Kaller, C.P.; Urbach, H.; Li, M.; Reisert, M. Frontal white matter architecture predicts efficacy of deep brain stimulation in major depression. Transl. Psychiatry 2019, 9, 197. [CrossRef]

70. Riva-Posse, P.; Choi, K.S.; Holtzheimer, P.E.; McIntyre, C.C.; Gross, R.E.; Chaturvedi, A.; Crowell, A.L.; Garlow, S.J.; Rajendra, J.K.; Mayberg, H.S. Defining critical white matter pathways mediating successful subcallosal cingulate deep brain stimulation for treatment-resistant depression. Biol. Psychiatry 2014, 76, 963-969. [CrossRef] 
71. Howell, B.; Choi, K.S.; Gunalan, K.; Rajendra, J.; Mayberg, H.S.; McIntyre, C.C. Quantifying the axonal pathways directly stimulated in therapeutic subcallosal cingulate deep brain stimulation. Hum. Brain Mapp. 2019, 40, 889-903. [CrossRef]

72. McInerney, S.J.; McNeely, H.E.; Geraci, J.; Giacobbe, P.; Rizvi, S.J.; Ceniti, A.K.; Cyriac, A.; Mayberg, H.S.; Lozano, A.M.; Kennedy, S.H. Neurocognitive Predictors of Response in Treatment Resistant Depression to Subcallosal Cingulate Gyrus Deep Brain Stimulation. Front. Hum. Neurosci. 2017, 11, 74. [CrossRef] [PubMed]

73. Quraan, M.A.; Protzner, A.B.; Daskalakis, Z.J.; Giacobbe, P.; Tang, C.W.; Kennedy, S.H.; Lozano, A.M.; McAndrews, M.P. EEG power asymmetry and functional connectivity as a marker of treatment effectiveness in DBS surgery for depression. Neuropsychopharmacol. Off. Publ. Am. Coll. Neuropsychopharmacol. 2014, 39, 1270-1281. [CrossRef] [PubMed]

74. Broadway, J.M.; Holtzheimer, P.E.; Hilimire, M.R.; Parks, N.A.; Devylder, J.E.; Mayberg, H.S.; Corballis, P.M. Frontal theta cordance predicts 6-month antidepressant response to subcallosal cingulate deep brain stimulation for treatment-resistant depression: A pilot study. Neuropsychopharmacol. Off. Publ. Am. Coll. Neuropsychopharmacol. 2012, 37, 1764-1772. [CrossRef]

75. Lujan, J.L.; Chaturvedi, A.; Malone, D.A.; Rezai, A.R.; Machado, A.G.; McIntyre, C.C. Axonal pathways linked to therapeutic and nontherapeutic outcomes during psychiatric deep brain stimulation. Hum. Brain Mapp. 2012, 33, 958-968. [CrossRef] [PubMed]

(C) 2020 by the authors. Licensee MDPI, Basel, Switzerland. This article is an open access article distributed under the terms and conditions of the Creative Commons Attribution (CC BY) license (http://creativecommons.org/licenses/by/4.0/). 